\section{EL IAPH aporta su experiencia en el Taller Internacional sobre Gestión del Patrimonio Inmaterial}

El Instituto Andaluz del Patrimonio Histórico participó durante el pasado mes de mayo, en la semana del 17 al 21, en el Taller Internacional sobre Gestión del Patrimonio Inmaterial, celebrado en la ciudad de Quito (Ecuador) y organizado por el Ministerio Coordinador de Patrimonio y el Instituto Nacional de Patrimonio Cultural, en colaboración con la Organización de las Naciones Unidas. El debate giró en torno a la identificación de los bienes inmateriales, sus problemáticas fundamentales así como la formulación de líneas de acción respecto a dicho patrimonio.

El objetivo fundamental de este encuentro fue el de construir de forma colectiva y con una metodología participativa, las bases para la elaboración de las políticas públicas que guien a la gestión y revalorización del patrimonio inmaterial en el país.

Durante toda la semana se debatieron puntos de vistas diversos por parte de diferentes tipos de actores sociales participantes para detectar problemáticas, causas y directrices que pudieran convertirse en posibles políticas públicas para la salvaguarda de este patrimonio cultural inmaterial.

El fortalecimiento institucional se consideró como una premisa necesaria para poder llevar a cabo de manera correcta y coordinada estas medidas. Para la formulación efectiva de dichas políticas de gestión se ha creado una comisión presidida por el Ministerio Coordinador de Patrimonio que liderará este proceso en el

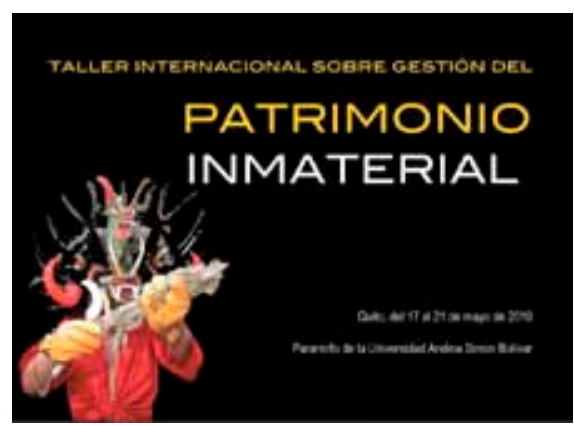

Detalle del cartel del Taller que participarán varias instituciones como el CONESUP, Universidad Salesiana, SENACYT, entre otras.

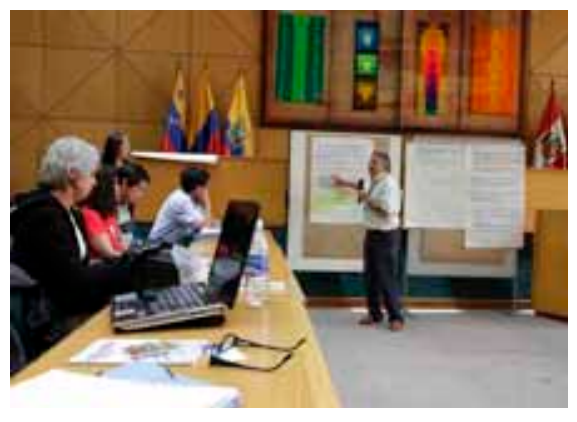

Uno de los numerosos encuentros que se organizaron durante el Taller. Fuente: Ministerio Coordinador de Patrimonio de Ecuador

Los organizadores del seminario valoraron muy positivamente las aportaciones del Instituto Andaluz del Patrimonio Histórico (IAPH), del Instituto de Patrimonio Histórico Artístico Nacional de Brasil (IPHAN) y del CRESPIAL (Centro regional para la Salvaguarda del Patrimonio Inmaterial de América Latina) a través de la participación de sus representantes en este seminario, Gema Carrera, Mônia Silvestrin y Silvia Martínez respectivamente, así como las aportaciones de la doctora Mónica B. Rotman de la Universidad de Buenos Aires para el ámbito temático de las artesanías.

Asimismo, los organizadores, plantearon una interesante fórmula de trabajo haciendo partícipes fundamentales a las instituciones invitadas tanto en las conferencias introductorias durante la primera jornada de trabajo, como a lo largo de toda la semana, en las mesas sectoriales de debate, coincidentes con los cinco ámbitos temáticos para el patrimonio inmaterial que propone la UNESCO en la Convención del 2003, así como en las reuniones plenarias para la puesta en común y la formulación de las conclusiones finales el trabajo.

De forma general, las instituciones invitadas así como los participantes, insistieron en la necesidad de conocimiento, sensibilización social y fortalecimiento de mecanismos de transmisión a través de la educación formal e informal como herramientas fundamentales para la salvaguarda de patrimonio inmaterial; la importancia del diálogo entre las diferentes instituciones culturales y el fortalecimiento de las mismas para trabajar de forma coordinada; una mayor participación de los grupos sociales y la creación de los mecanismos de participación necesarios para hacerlo posible; la formación de técnicos y el reconocimiento de los portadores del Patrimonio Cultural Inmaterial.

El enriquecimiento fue mutuo porque la metodología participativa de trabajo planteada por los anfitriones permitió hacernos partícipes de un proceso de trabajo muy interesante y fructifero, en el que en un breve período de tiempo, una semana, de forma colectiva, como el tema merece, a través de la participación de agentes sociales de diversa procedencia académica y profesional, o de actores portadores de este patrimonio cultural, se ha hecho posible la detección de problemáticas fundamentales que afectan al patrimonio inmaterial, la formulación de líneas de acción, potencialmente aplicables, así como la identificación de los actores necesarios para llevarlas a cabo.

Gema Carrera Díaz

Centro de Documentación y Estudios del IAPH 